\title{
Dança Coral, Dança em Multidão
}

\author{
Camila Simonin \\ Universidade Federal do Rio de Janeiro - UFRJ e Faculdade Angel Vianna, Rio de Janeiro/RJ, Brasil \\ E-mail: camilasimonin@gmail.com \\ Lígia Tourinho \\ Universidade Federal do Rio de Janeiro - UFRJ e Faculdade Angel Vianna, Rio de Janeiro/RJ, Brasil \\ E-mail: ligia.tourinho@gmail.com
}

\section{Resumo}

Tendo como objeto de estudo a Dança-Coral e os Coros de Movimento labanianos, o artigo parte da seguinte pergunta: as práticas de coralidade desenvolvidas por Rudolf Laban, sobretudo durante a década de 1930 na Alemanha, podem ser lidas como uma dança de massas? Nesse sentido, o estudo procura, em um primeiro momento, desenvolver o conceito de massa e traçar um panorama histórico do desenvolvimento da Dança-Coral e dos Coros de Movimento em seu auge no século passado. É abordado ainda o contraponto da dança de massas a uma dança de multidão, apoiada no conceito homônimo desenvolvido pelos filósofos Antonio Negri e Michael Hardt.

\section{Palavras-chave}

Dança-Coral. Massa. Multidão. Rudolf Laban.
With the main object of this study being Laban's Dance and Movement Choirs, this article is set out with the following question: could the choir practices developed by Rudolf Laban, specially during the 1930 ' in Germany, be read as a dance of masses? For that purpose, the article searches, first of all, to address the 'mass' concept and map the historical progress of Movement Choirs as a project in its peak in the last century. Furthermore, it is also discussed in the text another perspective entitled "dance of multitude", based on the homonymous concept created by the philosophers Antonio Negri and Michael Hardt. Keywords Movement Choirs. Masses. Multitude. Rudolf Laban. 


\section{Como as massas se movem?}

O tema Interno-Externo refere-se à relação dinâmica entre o interno do indivíduo (Corpo, sensações, imagens, experiências etc) e o externo (Espaço, meio ambiente, outras pessoas, objetos, acontecimentos sociopolíticos, etc) em recíproca influência, alteração e redefinição. (FERNANDES, 2006, p. 265).

A definição do grande tema interno-externo colocada por Ciane Fernandes no livro O Corpo em Movimento (2006), acaba por alinhar as palavras "Corpo" e "experiência" com "Espaço" e "acontecimentos sociopolíticos", como exemplos de elementos implicados nessa relação dentro-fora. Esse artigo procura debruçar-se sobre a Dança-Coral, seus contextos de criação e estrutura desenvolvida nos Coros de Movimento nas primeiras décadas do século XX. Para isso, esses acontecimentos serão aqui vistos pela lente do grande tema citado em relação ao conceito de massa, desenvolvido pelos filósofos Antonio Negri e Michael Hardt, em seu artigo Para uma definição ontológica da Multidão (NEGRI, 2004) e no livro Multitude: War and Democracy in the age of Empire (NEGRI; HARDT, 2004).

Mil pessoas de quarenta e um Coros de Movimento, vindas de vinte e sete cidades diferentes, movendo-se simultaneamente em um estádio de esportes em 1936, imersas em um contexto sociopolítico que pautava e zelava pela definição da palavra povo como correlato da soberania de um determinado grupo - o povo alemão - operam uma dança de massa? Ao que tudo indica, sim. O ensaio geral de Tauwind und der neuen Freude, episódio ápice do acontecimento da Dança-Coral, promovida por Rudolf Laban, no entanto, acaba se revelando como ponto de início do declínio da prática de coralidade proposta pelo artista. Cancelamento da apresentação do grupo labaniano nas olimpíadas de 1936, interrupção do apoio ao trabalho do coreógrafo pelo Ministério da Propaganda, cessando as atividades dos Coros de Movimento, diretamente ligados a Laban, até a sua partida da Alemanha em 1937, devido à impossibilidade de ofertas de trabalho após a ruptura de seu contrato, e o fim de um período frutífero na história da Dança-Coral.

É importante colocar que a explicação mais sucinta, e que pareceu ser um súbito declínio da atividade da Dança-Coral na Alemanha nazista, é o fato desta não ter representado, ao menos nas olimpíadas de 1936, uma dança de massa, intuito das atividades culturais apoiadas pelo Ministério da Propaganda de Goebbels.

Nesse sentido, é importante primeiramente apontar que Negri (2004) reitera o conceito de massa como uma multiplicação indefinida de indivíduos. Ao propor a reunião de indivíduos e não singularidades, o que estaria implicado nessa ideia é um conceito de medida, de números e aglomerações. Sólida e coesa, a massa reúne um aglomerado sem conflito, uma vez que é formada por "partes que não se pode dividir": indivíduos. Cabe citar, portanto, que o conceito pressupõe organismos homogêneos, cujas partes não se movimentam necessariamente de maneira integrada, mas de forma igual.

Recapturando a lente do tema interno-externo, uma massa se move sem colocar em foco as relações entre o que há dentro-fora, mas é auto-reflexiva. Ou seja, diz respeito a ela mesma, em uma ação de olhar interno em meio a esse grupo. Esse olhar para dentro era um movimento antecedente ao período nazista, que percorria a Alemanha para a construção de uma identidade nacionalista em meio à crise econômica e política durante o período da República Weimar (1918 - 1933). Como veremos, é também essa preocupação com o que vem de dentro que ronda o trabalho de Rudolf Laban acerca das coralidades e que protagoniza o fim das danças corais labanianas no território alemão.

\section{Bewegungschor: os coros de movimento}

As danças corais labanianas faziam parte de um dos projetos de Laban em relação à dança, que podiam ser divididos a partir de três "R": Recreation, Research e Rehabilitation (Recreação, Pesquisa e Reabilitação). Essa divisão em três áreas de atua- 
ção do estudo do movimento é realizada no fim da carreira de Laban, segundo Valerie Preston-Dunlop (1998). Dessa maneira, a Dança-Coral faria parte do projeto de Recreação, onde profissionais de diversos setores se reunissem para uma ligação através do movimento, na busca de tornar a dança uma atividade cotidiana e popularizada, comum a todos.

Nesse sentido, a Dança-Coral tratava-se de uma coreografia em grupo na qual os integrantes compartilhavam algum aspecto em comum (DOERR apud DAL COL, 2018). Essa dança era visada para um grupo de leigos e não-leigos, cujos núcleos de atuação eram denominados Coros de Movimento. Para o artista, "a prática era intencionada de maneira a criar um lugar de comunhão através do movimento, onde aquele que dança atingiria um recém-despertado senso de movimento através do entusiástico e dedicado ato de performar o movimento" (LABAN apud BARTENIEFF; LEWIS, 1980, p. 139).

Os Coros de Movimento eram grupos organizados por Laban, distribuídos em diversas cidades da Alemanha, que em geral contavam com alunos e colaboradores do coreógrafo como líderes, que propunham temas de movimento para que o grupo pudesse segui-lo, muitas vezes com o auxílio da Labanotation, sistema de notação criado por Laban que procura descrever minuciosamente o movimento. Nessa perspectiva, instaurava-se uma dinâmica parecida com as de coro-corifeu, presentes na tragédia grega, no que tange à relação entre líder e demais membros de um Coro de Movimento. Segundo Bartenieff (BARTENIEFF; LEWIS, 1980, tradução nossa), os líderes davam estímulos de dança dentro de uma partitura estruturada, mas que permitia a improvisação e espontaneidade de cada performer e dessa forma, configurava-se como uma reafirmação grupal de uma experiência comum.

Para Dal Col (2018), as danças-corais labanianas não possuíam como objetivo a estética do idêntico, mas se utilizavam de uma estrutura coreográfica para sublinhar a ação de dançar junto. Também nesse sentido a principal área de atuação dos Coros de Movimento, além dos próprios encontros, eram apresentações em ocasiões festivas, festivais, eventos sociais e esportivos etc.

Assim, é possível perceber nas danças-corais labanianas um paradoxo de uma prática que existe para reforçar o caráter de reunião de massa - aglomeração de pessoas que ali se reúnem e se expressam pelo que possuem em comum - , mas uma certa rejeição à estética do idêntico e da homogeneização, sobretudo por essa última estar vinculada ao contexto da mecanização dos gestos e do trabalho da revolução industrial.

Além disso, revendo mais à frente a continuação do desenvolvimento do campo labaniano pós Rudolf Laban, é pensar o mecanismo de estruturação coreográfica a partir da kinetographie, mais especificamente da Labanotation, que visa o registro minucioso dos movimentos. Ainda que seja vital ressaltar: a análise e atuação dessas partituras podem ganhar pequenas alterações, sobretudo dentro das categorias de Esforço e Forma, que trabalham com os impulsos internos e relações do performer em movimento. Operando, dessa maneira, questões mais subjetivas do movimento - tanto de quem analisa e realiza a notação, quanto de quem lê e a performa - e, portanto, mais suscetíveis a pequenas, mas consideráveis, variações.

De igual forma, é curioso perceber, tantos anos depois, que a ferramenta de notação do motif, usado atualmente no campo labaniano, dentro do Sistema Laban-Bartenieff, serve muito bem para um trabaIho de Dança-Coral com construção coreográfica que escape à estética do homogêneo. Isso porque o que entra em questão na notação e leitura do motif é o que o movimento apresenta como essencial, abrindo ainda mais o leque de possibilidades de leitura no lugar de priorizar uma descrição detalhada ou registro. Permitindo, portanto, maior aproveitamento do que é singular no mover de cada um.

\section{Gemeinschaftstanz: dança comunitária}

Nós ultrapassamos os tempos de Eu e Você e nos tornamos o tempo de 'nós' — não que sejamos simplesmente uma massa, mas 
uma comunidade racial, liderada pelo fuhrer e nossa dança amadora significa liderar e ser liderado1. (KEW, 1999, p. 78, tradução nossa).

Em 1933, no início do governo nazista, Laban estava no auge de sua carreira como profissional da dança. Grande nome na organização de festivais, com suas práticas difundidas pelas Labanschules (escolas que ensinavam os pensamentos de Rudolf Laban e que eram dirigidas por aprendizes diplomados pelo coreógrafo, espalhadas por toda Europa) e pela companhia de dança Tanzbühne Laban, instalada em Berlim, além de já ter atingido cargos estatais de liderança na cena da dança teatral alemã.

$\mathrm{Na}$ busca pela ativação do sentimento de comunidade e comunhão de um único "corpo-Alemanha", as propostas já existentes de Coros de Movimento e Dança-Coral de Laban se mostraram um caminho promissor para uma expressão artística capaz de não só mobilizar uma grande quantidade de pessoas, mas que pudesse servir como ferramenta para união do povo alemão.

No entanto, o que fica evidente para Dal Col (2018) e outros pesquisadores do tema, são as discordâncias da proposta de coralidade de Laban com o projeto de criação de massas do governo nazista.

Apesar de ambas ideologias terem uma ênfase na questão da comunidade, as coletividades que cada uma pregava eram diferentes. Voltando à questão da coralidade, Mégevand afirma [que] 'seria coral uma tendência de composição que consistisse ora em singularizar a individualidade, ora em incorporá-la ao coletivo'. O nacional socialismo deixou claro que não havia lugar para incorporar as singularidades ao coletivo. Aquele que não se encaixasse no padrão cultuado pelo Nazismo deveria ser excluído e exterminado. (DAL COL, 2018, p. 81).

1 Essa citação, encontrada no artigo From Weimar Movement Choir to Nazi Community Dance: the rise and fall of Rudolf Laban's Festkultur, é um trecho da revista de dança Wir Tanzen, exemplar distribuído em 1936 em Berlim.
Até hoje, desdobrar o braço à frente alta em uma forma direcional arcada é lembrado como um gesto de saudação hitlerista. Fazer esse movimento físico implica até hoje, quase cem anos depois, em uma conversão de uma pessoa a um determinado grupo: o nazista. Associamos esse indivíduo anônimo a uma massa de pessoas. O grupo mais próximo a Hitler rapidamente notou a eficácia de associação entre movimento e pertencimento a uma massa, à qual deram o nome de comunidade. Ao movimento, vincularam a dança. Ao desejo de movimentar uma comunidade alemã inteira, as práticas de coralidade labanianas. Para pleno funcionamento da Dança-Coral como expressão nazista, o Ministério da Propaganda modificou o nome anterior dos Coros de Movimento (Bewegunschoir) para gemeinschaftstanz, que em alemão significaria dança comunitária.

Counsell (2004) faz a ressalva de que ao se utilizar do termo Gemeinschaft, comunidade, como reunião de um grupo, este possui um universo identitário comum, atuando não como um encontro arbitrário de pessoas - como os Coros de Movimento abriam margem para interpretação -, mas um aglomerado de indivíduos unidos por interesses semeIhantes. Nesse sentido, a ideia de uma dança comunitária agrega também um valor de organização social cujo senso de reconhecimento identitário era tão procurado pelo governo na Alemanha no período entre guerras. Tal organização grupal tinha como intuito a formação sólida de uma coletividade igual e unida, compreendendo também seu projeto higienista e excludente dos considerados não-arianos.

\section{Eram experiências e não produtos}

No material escrito na época, Laban indicou que ele não necessariamente gostaria de ter olhos críticos observando seu material inicial. Afinal, os Coros de Movimento foram feitos por e para as pessoas que nele dançavam e eram experiências e não produtos. (BRADLEY, 2008, p. 9, tradução nossa). 
Dal Col (2018) faz uma reflexão sobre a Dança-Coral como uma dança que contagia, que envolve seus praticantes em uma ação que "modifica os limites do corpo", tendo como primeiro objetivo promover a experiência do movimento, sem ter que lidar com espectadores. Para a crítica de dança Beda Prilipp (apud KEW, 1999), é difícil abordar a performance de Laban porque a mesma parece mais um ato festivo do que "um trabalho de arte". Counsell (2004), por sua vez, aponta que os eventos surgidos dos Coros de Movimento raramente foram realizados com intuito de serem vistos como performance.

De fato, a maioria dos relatos e documentos escritos de Laban acerca das danças corais e dos Coros de Movimento não apontava como objetivo a apresentação de uma performance ou espetáculo - tendo em consideração a autobiografia realizada pelo autor em Una vida para la danza (LABAN, 2001) e as biografias escritas por Bradley (2008) e Preston-Dunlop (1998). Não pressupunha, dessa forma, espectadores ou olhares externos. O que estava, inicialmente, em questão no projeto de coralidade labaniano, era a experiência da dança enquanto atividade recreativa, cotidiana e popular (que atingisse o maior número de pessoas possível). Ainda sobre o olhar interno-externo e por mais que suas atividades estivessem pautadas em uma estrutura coreográfica de um líder no coro de movimento, seus participantes eram encorajados a procurar motores internos. Assim, trabalhando novamente com os impulsos e diferentes formas de relação do performer com os espaços internos e externos a si (o que, dentro do Sistema Laban-Bartenieff, consideramos assuntos dentro das categorias Esforço e Forma). A partir dessa preocupação máxima, não é intuito maior aqui ver alguém que se move, mas experienciar o movimento de dentro.

Porém, o que foi revelado na prática com a expansão dos Coros de Movimento por todo o país foi a possibilidade de facilitar alguns aspectos do modo de produção e veiculação da Dança-Coral. Isso significando que, com estruturas coreográficas difundidas através da kinetographie, era mais fácil transmitir uma mesma coreografia para diversos Coros de Mo- vimento através dos seus diferentes líderes, sem precisar, para isso, de deslocamento de bailarinos. Uma vez compartilhada, a montagem de uma coreografia por 1000 pessoas - a imagem volumosa de massa tanto desejada pelas autoridades governamentais do setor de cultura da Alemanha nazista - ficou realizável mais facilmente. Além disso, a rede dos Coros de Movimento no território alemão permitia que um mesmo trabalho realizasse temporada sem precisar que um mesmo grupo viajasse a todos os estados, o que seria menos prático e mais custoso. Ao invés disso, os Coros de Movimento se deslocavam em suas proximidades, apresentando simultaneamente uma mesma coreografia em todo território nacional.

Dessa forma, ainda que não atendesse completamente aos seus propósitos originais, através da aliança com o governo de Hitler, Laban — à época já em torno dos seus 55 anos - conseguiu pôr em prática um dos projetos que o acompanhava desde o início de sua carreira: a popularização e maior alcance da dança enquanto atividade recreativa para os alemães.

"A frase chave é: 'o rosto desses dançarinos não está direcionado para fora, mas para dentro"' (KEW, 1999, p. 78, tradução nossa). Imagine, agora, a seguinte situação. Você entra em uma sala, deixaremos em aberto se nela existe um palco ou não, mas você se senta em uma cadeira a uma distância educada de uma pessoa que está deitada no chão. Outras pessoas que você não conhece te acompanham, também sentando-se em cadeiras ao seu lado. Estão todos ali para uma performance. A pessoa deitada no chão começa a se mover. Seus olhos estão fechados e não existe nenhuma parte do corpo dela que está em relação com você ou qualquer outra pessoa sentada nas cadeiras.

Ao contrário, ela começa respirando e você observa suas costas se expandindo e contraindo em um ritmo regular. Ela começa a variar as durações das inspirações e expirações, ora mais curtas, ora mais longas em recuperação. De toda forma, as respirações mais curtas te passam uma imagem de urgência e aflição que ela poderia estar sentindo. De repente, o ventre dela vai ao chão, modificando a 
posição fetal inicial em uma outra quase de bruços. Agora, ela ainda de olhos fechados, você ainda de olhos abertos observa seu tronco mastigar o chão, o corpo todo movendo-se como a partir das vísceras torcendo e contorcendo repetidamente. Algo muda em seu ritmo. Você vê agora ela engajar mais a coluna e outros pontos de partida ósseos. Durante todo esse tempo, você percebe momentos que podem ser lidos como dor, tristeza e também prazer. Não fica evidente quem sente e quem provoca essas sensações, mas elas estão lá. De acordo com você. A partir dessa conexão cabeça-cóccix, ela muda até de nível espacial, mas não estabelece em nenhum momento uma relação com as pessoas nas cadeiras. Não olha, aponta ou fala. Essas seriam interações com elementos externos que, ao menos para essa performance, não são importantes. A única coisa que transita entre o espaço interno e externo dela é o ar que mantêm sua vida e movimento. Ela deita com as costas no chão e move-se quase imperceptivelmente, mas em um ritmo regular, em uma sincronia muito específica. Você leva a mão ao próprio peito e percebe que o ritmo do seu coração é similar ao ritmo com que ela se move. A luz se apaga. Fim da performance.

A descrição fictícia acima fala sobre a relação entre uma performance realizada em shape flow ${ }^{2} \mathrm{e}$ alguém que a assiste: um espectador. Essa performance não se baseia, aparentemente, em passos e estruturas já concebidas, uma vez que parte das

2 Shape Flow é uma das possibilidades de Modos de Mudança de Forma dentro do Sistema Laban-Bartenieff (entendendo essa como uma abordagem estadunidense, oriunda, sobretudo do Instituto LIMS, em Nova York). A categoria Forma refere-se à pergunta "Com quem nos movemos?", analisando, portanto, modos de comunicação, estabelecimento de limites e variações no volume do corpo em movimento. Shape Flow, nesse sentido, diz respeito ao movimento em relação consigo mesmo. Um ponto interessante é a respiração, entendida na descrição como o único movimento de troca na performance entre o espaço interno e externo. Ainda que essa possa ser um dos pontos de vista acerca do movimento respiratório, ele também pode ser compreendido como aumento e diminuição do volume interno do corpo, constituindo-se assim, um movimento que falaria sobre espaço interno e não troca entre interno-externo. relações internas e de mudanças de volume interno do corpo, atualizadas e reiteradas constantemente - e que portanto não poderiam partir de uma estrutura coreográfica mais tradicional. Com essa descrição, visamos colocar em pauta a relação entre uma dança que parte de impulsos ou espaços internos e a plateia, que não é impedida de realizar suas próprias concepções e leituras da obra por esta não possuir referenciais externos (quem faz $\mathrm{e}$ para quem fez) explícitos e delineados. É justamente essa relação que pode ser percebida nas danças corais labanianas na década de 30 e que é responsável pelo seu declínio e fracasso enquanto projeto de dança de massa pretendida pelos nazistas.

A primeira falha da Dança-Coral de Laban ser considerada uma dança de massas em meio à Alemanha hitlerista é ela não estar pautada na já mencionada lógica do idêntico e não possuir um objeto externo bem definido. Laban procurou desenvolver dentro do seu projeto de coralidades estruturas coreográficas que partissem de impulsos internos, organizando esses movimentos em ações corporais no Espaço. Ainda que coreografadas, portanto, as danças corais e seus performers não eram uníssonos em seus movimentos nas apresentações como se pressupunha para uma massa homogênea e igual.

Para Prilipp (apud KEW, 1999), por conta dessa contemplação interna, o significado da dança perdia seu objeto de devoção, contrariando as expectativas do setor cultural nazista, que contava com a dança como uma expressão de reverência à figura externa de Hitler como líder da comunidade. Com a dança focada nesse "retornar para a casa", ou seja, voltar à face para os estímulos internos, ficava dúbio para a plateia qual era o objeto externo de admiração.

O segundo ponto a ser citado, em extrema relação com o primeiro, é a abertura de sentido das performances do coro de movimento. Como exemplificado acima, uma dança que trabalha a partir de motores e espaços internos não impossibilita a leitura e elaboração de sentidos por parte do espectador, que observou na descrição imagens de aflição, dor, prazer e tristeza realizadas pela performer. No entanto, aqui 
observamos a relação somente com um espectador - e não é garantia de que a maioria na plateia tenha assim compreendido e observado as sensações.

Da mesma maneira, as apresentações das danças corais deixavam seus sentidos e propósitos muito abertos à interpretação de seus espectadores. Para Kew, "as sequências de dança não eram ilustrações de nenhum evento específico. Isso deixaria a decifração da dança aberta a cada indivíduo membro da plateia. A dança de Laban era 'intelectual' no sentido de que poderia ser lida de diferentes maneiras" (KEW, 1999, p. 82, tradução nossa). Tal aspecto encorajava, dessa forma, o pensamento independente por parte de cada membro da plateia, o que falhava à mensagem ideológica do governo nazista que precisava ser transmitida "à massa" de maneira única, concisa, explícita, direta e sem dúvidas através da dança. Eis, então, a segunda falta dos Coros de Movimento enquanto projeto de dança de massas.

[...] fica evidente enquanto um continuum de produtos culturais, indo do próprio discurso - ideias apresentadas como ideias - à ação: real, corpos móveis engajados em práticas tangíveis. Enquanto o primeiro tende a um nomear explícito, o outro em geral envolve encorpar, subjetividade social inscrita na lógica da formação somática. [...] É dessa perspectiva que eu considerarei as danças de Bewegungschören ${ }^{3}$. Coros de Movimento, irei argumentar, são a expressão somática de uma consciência social específica, na qual existe, inclusive, enquanto crítica das condições que a deram origem. (COUNSELL, 2004, p. 155, tradução nossa).

Colin Counsell traz ainda o último ponto considerado como desviante do projeto de dança de massas ao considerar nas danças-corais uma re-modulação da experiência do espectador. Isso se deve a uma mudança nas relações sociais da performance - que podemos apontar como vanguardistas -, realizadas por Laban ainda na década de 30. Para Counsell (2004), o espectador das danças corais estava inscrito numa reconfiguração que permitia um maior

3 Outro nome anterior para Coros de Movimento. ativamento da plateia, sem que para isso o coreógrafo tivesse modificado as relações espaciais entre palco e espectador ou tivesse que fisicamente se mover.

As relações descritas pelo autor implicariam uma postura performativa de atividades interpretativas, visto que, com os sentidos abertos para decifração da plateia, o espectador assumiria um papel participante de leitura, tornando-o também colaborador da experiência que ali se apresenta ao Ihe atribuir um sentido possível. Essa participação que não necessariamente precisa de uma atuação literal e física formaria, dessa forma, um processo de encorpamento de consciência social e, por isso, são analisadas por Counsell como expressões somáticas sociais.

Esse terceiro ponto sinalizado aqui como "falha" para a construção de massas é assim analisado na medida em que atribui para os espectadores uma relação não dividida e não metafísica entre corpo-mente, mas argumenta que através de atividades psíquicas assumidas enquanto espectador diante de uma experiência, é possível chegar a encorpamento de ações físicas de forma integrada. Essa integração de ações corpo-mente também atuaria, portanto, contra uma formação de massas. Isso porque reforça as singularidades e especificidades de cada um, tendo "cada momento permeado com o reconhecimento que alguém está em uma performance com outros, parte de um projeto maior, comum" (COUNSELL, 2004, p. 162, tradução nossa), da qual também é responsável.

\section{Os substitutos}

Uma vez comprovado que as danças-corais labanianas não seriam eficazes enquanto expressão cultural de construção de massa no nazismo, é válido trazer à tona os meios que se provaram mais eficientes para o mesmo intuito, segundo o ministério de propaganda de Goebbels.

A começar pelo evento das olimpíadas de 1936, uma vez que Tauwind und der neuen Freude havia sido impedido de se apresentar após a realização de seu ensaio geral. Carole Kew (1999) aponta que The Thinsgspiel, um drama coral que utilizava como 
recursos cênicos falas em grupo e movimentos de massa (uníssonos e homogêneos) entrou como um substituto do espetáculo de Laban. A performance dramática utilizava-se da estrutura grega clássica de um anfiteatro em 1936 para contar uma narrativa que construía uma analogia entre Hitler e um líder bom e eterno. Eles re-encenaram de maneira metafórica eventos históricos, transmitindo de forma objetiva a mensagem de punir os maus líderes passados e celebrar o bom líder presente e futuro.

No entanto, com o prenúncio da segunda guerra e o avançar do governo de Hitler, ficou cada vez mais evidente para o setor cultural nazista que suas expressões artísticas de construção de massas precisariam ser mais rentáveis, com maior capacidade de expansão e viabilidade em tempos de guerra. Nesse sentido, o rádio e o filme mostraram-se veículos de expressão cultural mais adequadas à propaganda. Além de sua maior praticidade de circulação, o recorte objetivo do que cada espectador vai ver ou ouvir, ou ainda sua estabilidade quanto ao que era transmitido (impassível de mudanças, uma vez que a obra estava "pronta") mostraram-se mais fiéis ao que se pretendia com a propaganda do governo.

Simultaneamente às mídias de massa, a marcha militar provou-se uma expressão de movimento em meio às celebrações e festivais governamentais. Como um reflexo às políticas de rearmamento e mobilização popular à guerra, ela servia para os propósitos de expressão cultural para construção de massas. Ainda segundo Kew (1999) em seu artigo "From Weimar Movement Choir to Nazi Community Dance: the rise and fall of Rudolf Laban's Festkultur", agora, a dança era vista pelo ministério de propaganda como um "prazer inofensivo", enquanto a marcha era uma transformação corporal de um indivíduo participante de um aglomerado igual. Os Coros de Movimento foram substituídos, assim, pela conformidade e anonimidade da marcha, em apoio à política expansionista direcionada para a guerra.

\section{Rudolf Laban e o Nazismo: a quem serviu a Dança-Coral ?}

\begin{abstract}
Não se trata de condenar Laban ao rótulo de nazista ou colocá-lo em uma posição de martírio, heroísmo e vitimismo, mas de entender qual era o interesse do projeto nazista nas Danças-Corais e como essas foram utilizadas em favor de uma propaganda do regime. (DAL COL, 2018, p 67).
\end{abstract}

A relação entre Rudolf Laban, a Dança-Coral e o regime nazista é um tema pouco debatido dentro do próprio campo labaniano, justamente por não ter coerência com a origem da Dança-Coral, em Ascona, e também por se tratar de uma temática delicada, porém importante, que envolve um dos maiores pensadores da Dança com um dos terríveis períodos da História.

No Monte Veritá, essa prática de coralidades em meio à primeira guerra, demonstrava o anseio e ideais de Laban ao trazer a cultura do corpo para a dança como uma expressão interna, que é externalizada através do movimento. Com isso, promovia também seu desejo de que o dançar fosse uma atividade cotidiana e comum a todos os seres humanos, afastando-os de uma vida mecanizada no trabalho e na cidade.

Com a Körperkultur em seu auge na Alemanha, o interesse político sobre a figura de Laban e sua dança livre aumentou, tendo em vista sua constante ascensão e ocupação de cargos de liderança em cena da dança teatral alemã. Laban passou a ser procurado por artistas de toda a Europa, foi galgando postos cada vez mais importantes e descobriu que, aliando-se aos interesses do nacional-socialismo, teria a oportunidade de concretizar os projetos que vinha elaborando desde o início de sua carreira. (SCIALOM, 2017, p. 29-30).

A pesquisadora aponta que Laban teria um contrato de trabalho, patrocínio governamental para pesquisar, criar e lecionar. Em muitas biografias do dançarino feitas por integrantes do campo labaniano, como Valerie Preston-Dunlop, por exemplo, são colocados diversos períodos da vida de Laban em que o artista enfrenta dificuldade de estabilidade financeira, 
em meio também a períodos de depressão. É com essa perspectiva que Scialom afirma que Rudolf Laban manteve seu ideal de disseminar a dança como arte e manifestação comunitária, aproveitando-se das oportunidades que surgiram para se tornar referência da dança alemã na década de 1930 "apesar de estar em meio à ideologia nazista" (SCIALOM, 2017, p. 30).

Para observar essa relação através de um outro ponto de vista, o livro Hitler's Dancers: German Modern Dance and the Third Reich apresenta, através das pesquisadoras Lilian Karina e Marion Kant - a primeira tendo vivido o período histórico e sendo ela mesma uma das artistas que fugiu da Alemanha Nazista e a segunda como historiadora da dança, especialista em danças feitas em exílio - perspectivas mais duras sobre a figura de Laban, em aberta e explícita crítica à ascensão da Dança-Coral na Alemanha no período entre guerras.

A arte tem sempre uma relação íntima com a sociedade que carrega e leva os símbolos e signos até as épocas que a sucedem. $O$ comportamento dos grandes criadores da dança moderna alemã mostra o quão rapidamente a arte pode ser corrompida ao se aproximar do poder e da riqueza e o quão fictícia é a ideia da arte pela arte na prática. [...] O último trabalho coral de Laban, Of the warm wind and New Joy, deveria realizar a abertura dos jogos olímpicos. Após o ensaio geral, Goebbels ordenou que a apresentação fosse cancelada. De acordo com vários documentos de testemunhas e posteriores historiadores, essa decisão de Goebbels de cancelar o trabalho prova que Laban era um anti-nazista. Estava subentendido que ele era um "pacifista" ou um "socialista". [...] Todos esses relatos, que são usados como evidências, não dizem a verdade. Laban recebeu um contrato legítimo do Ministério da Propaganda e foi funcionário do governo até 1937. (KANT; KARINA, 2003, p. XI; 6; 18, tradução nossa).

São poucos os materiais que falam sobre as danças corais de Rudolf Laban em seu auge no período de 1933 a 1936. São poucos os materiais que falam sobre a relação dessa que foi uma das figuras mais importantes para a história da dança e do estu- do do movimento e o nazismo. Os relatos acima são de profissionais atuantes no campo da dança e cada um assume, à sua maneira, um olhar sobre essa última relação. Curioso perceber essa defesa da primeira autora, quase um ato de escusar o artista de seu contexto, também em defesa ao campo de pesquisa do qual faz parte. Às autoras seguintes, com objetivos completamente distintos e ataques diretos, não preciso acrescentar a informação de que não fazem parte do campo de pesquisadores do campo labaniano.

O intuito de expor as condições de crescimento da Dança-Coral enquanto projeto de formação de massas e o quanto ambos Rudolf Laban e o governo nazista se beneficiaram da mesma, enquanto veículo de transmissão de ideologias, não se trata aqui de uma maneira de ignorar as contribuições do coreógrafo para seu próprio campo ou rechaçá-las. Até mesmo levando-se em conta o caráter genealógico das práticas corporais do Sistema Laban-Bartenieff para o trabalho dessas autoras que aqui escrevem.

Este artigo pretende, ao contrário, trazer à tona o contexto histórico da prática da Dança-Coral e o quanto é importante refletir sobre as relações de poder e violência que cercaram esse projeto de formação de grupos. Como perspectiva final, trago Valerie Preston-Dunlop, artista do movimento e figura importante dentro do campo labaniano, realizados em seu livro Laban, an extraordinary life (1998).

\begin{abstract}
Alguém poderia perguntar, por que Laban não protestou? Por que ele não deixou seu emprego ao invés de participar dessa "limpeza" absurda? Por que ele não deixou o país, emigrou ali mesmo naquele momento? Ao contrário de muitos artistas, ele não perdeu seu emprego, seu trabalho não foi limitado como o de Kandinsky ou Brecht, ele não foi acusado de "Bolchevismo" ou comunismo, como foi Martin Gleisner, ele não tinha antepassados judeus como o editor do Der Tanz, Joseph Lewtan, e ele até esse momento não havia sido acusado de nenhum delito, seja ideológico ou racial. Para muitos, o horror era visto como tão irracional, tão bizarro, que certamente não duraria. (PRESTON-DUNLOP, 1998, p. 174, tradução nossa).
\end{abstract}


Preston-Dunlop também aponta para a estabilidade financeira e emprego até o ano de 1936 como um dos grandes motivos. Para a autora da biografia, entre os artistas que obtinham do privilégio racial de escolha, havia três categorias principais de ação: os que partiam; os que ficavam e apoiavam; os que ficavam e sobreviviam. Para ela, Laban ocupou esse terceiro grupo. Evidentemente, essa sobrevivência era uma alternativa de manter seus empregos em cargos públicos, visto que serem funcionários do governo e confrontá-lo não poderiam ser ações simultâneas na administração nazi-fascista. No topo da árvore artística, como a autora coloca, Laban decidiu "aguardar os eventos passarem" (PRESTON-DUNLOP, 1998, p. 177).

No capítulo 10, intitulado "Sobrevivência", Preston-Dunlop (1998) relata o período de 1934 a 1937, onde explicita que Laban sabia o suficiente de seus empregadores e como sua reputação - à época já internacional - seria usada para promover não somente a dança, mas a Dança-Coral enquanto dança comunitária e dogma nazista. Ela afirma também que seria esse caráter internacional e expoente que permitiria o uso, porém não abuso, da figura de Rudolf Laban pelos nazistas.

Em uma anedota do dia $1^{\circ}$ de julho de 1934 , Preston-Dunlop (1998, p. 181) conta sobre o episódio de uma reunião em que Laban se sentou à direita do führer que, após uma conversa animada, comentou "Eu nunca imaginei que dançarinos fossem pessoas tão inteligentes", ao que o artista respondeu "Não é impressionante quão preconceituosas as pessoas são? Eu pensava a mesma ideia equivocada em relação aos chefes de Estado".

Após o ensaio das Olimpíadas em 1936, já descrito acima, as conversas não foram mais tão animadas, ainda que Laban não tenha sido expulso do país. As autoridades foram atrás de sua ascendência ariana, posteriormente documentada e confirmada. Mas o que, de fato, provocou a saída do país, para a autora, foi a pergunta feita sobre suas relações com a maçonaria. Laban havia respondido ter sido membro da Ordo Templi Orientis entre os anos de 1917 e 1918.
Por mais que as ações de perseguição só condenassem adesão a esses grupos e organizações secretas após 1933, alguém iria ter que lidar com Laban e ninguém parecia querer assumir essa responsabilidade.

$\mathrm{O}$ artista entra então em um de seus períodos recorrentes de depressão e renuncia sua posição como líder do setor de Dança, tornando-se disponível apenas como especialista para ocasiões especiais. Ele ainda recebe pagamento mínimo até o limite de validade de seu contrato, em 31 de março de 1937 (PRESTON-DUNLOP, 1998, p. 199). Entre março e agosto desse ano, as autoridades prometeram suspensão da licença para escolas e profissionais da dança que acolhessem Laban como coreógrafo. A alternativa restante para a sua permanência na Alemanha, era, então, a associação e apoio explícito ao Partido Nazista, ao que o coreógrafo decide partir do país em 07 de agosto de 1937.

Após ler esses materiais, algumas constatações nos parecem importantes. As duas primeiras, inegáveis: o valor e influência do trabalho teórico-prático de Laban, que admite reverberações até hoje nas mais distintas áreas que lidam com o movimento e o quanto o coreógrafo se beneficiou e conseguiu concretizar muito de seu projeto para a dança através da ascensão do governo nazista. Também é notável ao entrar em contato com esses escritos, que as verdadeiras intenções de Laban não poderiam - tão posteriormente - ser decifradas. Ingenuidade do papel que exercia ou parcial aliança ideológica, o que se mostra relevante é o contexto pelo qual esse conjunto de práticas foi fomentado, sem retirar disso o seu valor enquanto contribuição, mas também sem esquecer o que a possibilitou. 
Além disso, é interessante notar que as danças-corais serviram também a mais pessoas do que somente as apresentadas aqui ${ }^{4}$. Mais do que isso, elas se mostram um modo de criação, produção e expressão extremamente válido até os dias de hoje.

\section{Estar em multidão}

A multidão não é representável, ela apresenta sua face monstruosa.

(NEGRI, 2004, p. 17).

Até aqui, tivemos como foco o trabalho de Rudolf Laban e sua Dança-Coral na década de 30 , inserida em um contexto e projeto de formação de massas. Ao sugerir o conceito "massa", trouxemos a perspectiva dos filósofos Negri e Hardt, que discutem essa concepção alinhada à palavra povo em contraponto à ideia de multidão. Para Negri e Hardt (2004), o povo é representado a partir de sua unidade e tentativa homogeneizante ao passo que a multidão desafia qualquer representação por se tratar de uma multiplicidade incomensurável. Para os autores, esse segundo tipo de coletividade nem mesmo admite um processo contratual, visto que tal medida estabelece um início e até mesmo um fim, enquanto a multidão não possui acordos de tal ordem. Ela está sempre em movimento e em processo de continuidade.

Fica evidente, ao ver os projetos de formação de massa, que não há ingenuidade em pensar que tal grupo homogêneo não possua entre si diferenças. No entanto, o que fica como questão central da multidão é a organização de uma coletividade que surja a partir das divergências entre suas inúmeras partes, seus inúmeros cen-

4 A citar como exemplo Martin Gleisner, já supracitado, responsável pela fundação do Coro de Movimento Volkshochschule, uma instituição socialista localizada na cidade de Gera. Influenciado pelo socialismo, Gleisner acreditava na arte do movimento como possibilidade para a transformação da sociedade e do diletantismo. Foi ele quem fundou também o Coro de Movimento Turíngio, um grupo inicialmente formado por trabalhadores das indústrias da região, predominantemente homens jovens (PRESTON DUNLOP, 1988). tros. Em multidão, a pluralidade acaba por tornar-se seu mecanismo de atuação enquanto grupo.

Desta forma breve, englobamos o conceito de multidão às análises dos movimentos de grupo, fazendo, assim, uma aposta que se construir em um coletivo com tais características - caótico, monstruoso e plural - é uma disputa por maiores ações em busca de liberdade. Mais do que isso, acreditamos ser enriquecedor visualizar-se em multidão, em eterna negociação dentro-fora, uma vez que são essas trocas entre interno-externo aquelas capazes de gerar mudanças.

Encaminhamos, por fim, após o apanhamento dos contextos aqui feitos e levando em conta os contextos que se inscrevem na escrita deste artigo, uma proposta, vinda ela mesma do campo labaniano. O verbo "To cope" é usado por Bartenieff (BARTENIEFF; LEWIS, 1980) no título de uma de suas principais contribuições escritas ao campo de estudos do movimento. To cope: lidar de maneira perspicaz com situações e circunstâncias, contender, não estar alheio. Dessa forma, promovemos a ação de estar em multidão como uma maneira de lidar de maneira perceptiva com o mundo que nos cerca a partir de ações. Tendo em conta que para estarmos vivas, respiramos. E que esse suporte respiratório fala muito além da troca de ar, mas mostra também que a vida se sustenta no movimento entre o que há dentro e fora. Se sustenta em perceber, agir e mover os entres.

\section{Referências}

BARTENIEFF, Irmgard; LEWIS, Doris. Body Movement: Coping with the Environment. Gordon and Breach Science Publishers, New York, 1980.

BRADLEY, Karen K. Rudolf Laban. Routledge, 2008.

COUNSELL, Colin. Dancing to Utopia: Modernity, Community and the Movement Choir. Dance Research: The Journal of the Society for Dance Research, Vol. 22, No. 2: p. 154-167, 2004. 
DAL COL, Francisco. Dança-Coral: uma porta de entrada para o pensamento de Rudolf Laban. Monografia (Pós Graduação Lato Sensu em Sistema Laban/Bartenieff). Faculdade de Dança Angel Vianna, Rio de Janeiro, RJ, 2018.

FERNANDES, Ciane. O Corpo em movimento: o sistema Laban-Bartenieff na formação e pesquisa em artes cênicas. Annablume, 2006.

KARINA, Lilian; KANT, Marion. Hitler's dancers: German modern dance and the Third Reich. Berghahn books, 2003.

KEW, Carole. From Weimar Movement Choir to Nazi Community Dance: The Rise and Fall of Rudolf Laban's "Festkultur". Dance Research: The Journal of the Society for Dance Research, Vol. 17, No. 2: p. 73-96, 1999.

LABAN, Rudolf. Una vida para la danza. México: Ríos y raíces, 2001.

NEGRI, Antonio. Para uma definição ontológica da Multidão. Revista Lugar Comum, 2004. Disponível em: http://www.e-papers.com.br/sumario.asp?codigo_produto=487. Acesso em: 01 mai. 2020.

NEGRI, Antonio; HARDT, Michael. Multitude: war and democracy in the Age of Empire. Nova York: Penguin Group, 2004.

PRESTON-DUNLOP, Valerie. Rudolf Laban: An extraordinary life. London: Dance Books, 1998.

SCIALOM, Melina. Laban Plural: Arte do movimento, pesquisa e genealogia da práxis de Rudolf Laban no Brasil. Summus Editorial, 2017.

Recebido: $14 / 06 / 2020$

Aceito: 31/07/2020

Aprovado para publicação: 17/11/2020
Este é um artigo de acesso aberto distribuído sob os termos de uma Licença Crea- tive Commons Atribuição 4.0 Internacional. Disponível em: <http://creative commons.org/licenses/by/4.0>.

This is an open-access article distributed under the terms of the Creative Commons Attribution License 4.0 International. Available at: <http://creative commons.org/licenses/by/4.0>.

Ce texte en libre accès est placé sous licence Creative Commons Attribution 4.0 International. Disponible sur: <http://creativecommons.org/licenses/by/4.0>. 